\title{
Energy Power Efficient Vedic Multiplier Design on 28nm FPGA Using Vedic Formula ANURPYENA
}

\author{
Arushi Aggarwal \\ Dept of ECE, Chitkara University, Chandigarh, India \\ missarohi4@gmail.com
}

\begin{abstract}
The paper is about the designing of the low power energy proficient Vedic multiplier on $28 \mathrm{~nm}$ field programmable gate array. Our motive here is to design a low power energy efficient design and for that reason, we are doing our study on different types of LVCMOS IO standards: LVCMOS_15, LVCMOS_18, LVCMOS_25, LVCMOS_33. To verify the thermal aware design we have taken 5 different temperatures from five different areas $10^{\circ} \mathrm{C}, 25^{\circ} \mathrm{C}, 40^{\circ} \mathrm{C}, 55^{\circ} \mathrm{C}, 70^{\circ} \mathrm{C}$. There is $3.73 \%$, $3.21 \%, 3.005 \%, 3.002 \%$ reduction in leakage power, there is $0.544 \%, 0.71 \%, 3.63 \%, 1.21 \%$ reduction in MAT and there is $73.74 \%, 70.43 \%, 52.00 \%, 61.93 \%$ reduction in JT for LVCMOS_15, LVCMOS_18, LVCMOS_33, LVCMOS_25 correspondingly as we level down ambient temperature from $70{ }^{\circ} \mathrm{C}$ to $10^{\circ} \mathrm{C}$.
\end{abstract}

KEYWORDS : - Vedic Math's, Low Power, Multiplier, Energy Efficient, FPGA.

\section{INTRODUCTION}

Multiplication is one of the most imperative hardware chunk in any Digital system in order to perform different operations like frequency filtering, frequency transformation and many other. Some of the major arithmetical operations by the multiplier in the Digital systems are to multiply and accrue. Apart from digital systems, it is a vital wedge in Image Processing systems, Arithmetic and Logical Unit of the processors etc. The former processors were not having a Multiplier block, instead they used multiply routines. However with the enhanced levels of amalgamation in the newest VLSI circuits gradually, the chore of conniving a multiplier block has begin getting enormous fidelity in the devise of digital systems. An additional trait of the multiplier which should be given a lot of anxiety in conniving of the system is Power debauchery. A towering throughput and high performance energy efficient multiplier for the Field Programmable Gate Array (FPGAs) is being proposed in this paper. IO standard play a significant role in power dissipation of design. For that cause, we are going to choose the most energy proficient IO standards in LVCMOS family they are LVCMOS15, LVCMOS18, LVCMOS25 and LVCMOS33. To scrutinize the transformation in this electronic + arithmetic design made on changing the ambient temperature [4-7] i.e. to verify the thermal aware design we have taken 5 different temperatures from five different areas. The key feature of this projected design is that it is based on "Ancient Indian Vedic Mathematics". This paper tells of "Anurpyena Sutra” which can increase the speed of multiplier by reducing the number of repetitions. 
Anurpyena : The upa-sutra 'ANURPYENA' means proportionality. This sutra is extremely helpful to find products of two numbers when both of them are near the common bases that is powers of base 10

Example:

In this Method we will take 50 as our working again, and we will take it as 5 x $10=50$. We write the numbers out, all along with their differences from our operational base (50).

$42-8$

$48-2$

We cross add/subtract to get 40 . This time however, since we are treating it as $5 \times 10$ $=50 \ldots$ we multiply $40 \times 5$. When we do this we get 200 .

$42-8$

$48-2$

$200 /$

Since we took this as $5 \times 10$, our right-hand side can only have one digit (there's only one zero in 10). So we multiply $(-8) \times(-2)=16$, and this becomes our right-hand side.

$42-8$

$48-2$

$200 / 16$

Answer: 42 x $48=2016$.

\section{Analysis of Maximum Ambient Temperature and Junction Temperature}

\section{A. Analysis of MAT, Junction temperature and Leakage power for various IO standards}

Table 1:Analysis of MAT ,JT, LP for LVCMOS_18 IO standard

\begin{tabular}{|l|l|l|l|}
\hline & MAT & JT & POWER \\
\hline $10^{\circ} \mathrm{C}$ & 69.6 & 25.4 & 7.517 \\
\hline $25^{\circ} \mathrm{C}$ & 69.5 & 40.5 & 7.537 \\
\hline $40^{\circ} \mathrm{C}$ & 69.5 & 55.5 & 7.576 \\
\hline $55^{\circ} \mathrm{C}$ & 69.3 & 70.7 & 7.647 \\
\hline $70^{\circ} \mathrm{C}$ & 69.1 & 85.9 & 7.767 \\
\hline
\end{tabular}

There is $0.71 \%, 70.43 \%, 3.21 \%$ reduction in MAT,JT,POWER respectively when we scale down ambient temperature from $70{ }^{\circ} \mathrm{C}$ to $10^{\circ} \mathrm{C}$ for LVCMOS_18 IO standard.

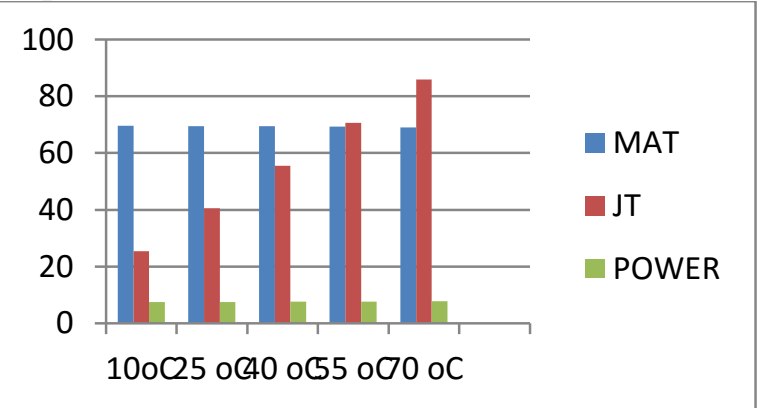

Figure 1:Graphical representation of MAT, JT, LP for LVCMOS_18 
ISSN: 2456-0065 DOI: 10.21058/gjet.2015.1201

Table 2:Analysis of MAT ,JT,LP for LVCMOS_25 IO standard

\begin{tabular}{|l|l|l|l|}
\hline & MAT & JT & POWER \\
\hline $10^{\circ} \mathrm{C}$ & 57.7 & 37.3 & 13.288 \\
\hline $25^{\circ} \mathrm{C}$ & 57.7 & 52.3 & 13.322 \\
\hline $40^{\circ} \mathrm{C}$ & 57.5 & 67.5 & 13.385 \\
\hline $55^{\circ} \mathrm{C}$ & 57.3 & 82.7 & 13.493 \\
\hline $70^{\circ} \mathrm{C}$ & 57.0 & 98.0 & 13.699 \\
\hline
\end{tabular}

There is $1.21 \%, 61.93 \%, 3.002 \%$ reduction in MAT,JT,POWER when we range down ambient temperature from $70{ }^{0}$ to $10^{\circ} \mathrm{C}$.

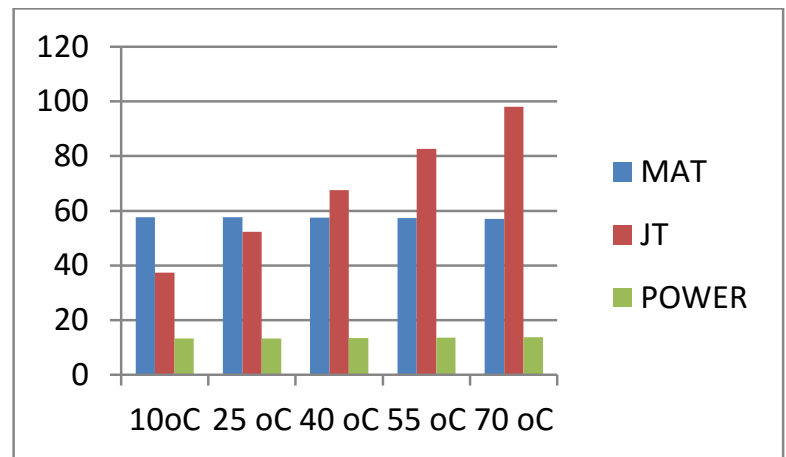

Figure 2: Graphical representation of MAT, JT, LP for LVCMOS_25

Table 3: Analysis of MAT, JT, LP for LVCMOS_33 IO Standard

\begin{tabular}{|l|l|l|l|}
\hline & MAT & JT & POWER \\
\hline $10^{\circ} \mathrm{C}$ & 38.5 & 56.5 & 22.658 \\
\hline $25^{\circ} \mathrm{C}$ & 38.4 & 71.6 & 22.731 \\
\hline $40^{\circ} \mathrm{C}$ & 38.1 & 86.9 & 22.855 \\
\hline $55^{\circ} \mathrm{C}$ & 37.7 & 102.3 & 23.055 \\
\hline $70^{\circ} \mathrm{C}$ & 37.1 & 117.9 & 23.360 \\
\hline
\end{tabular}

There is $3.63 \%, 52.00 \%, 3.005 \%$ reduction in MAT,JT,POWER when we range down temperature from $70{ }^{\circ} \mathrm{C}$ to $10{ }^{\circ} \mathrm{C}$.

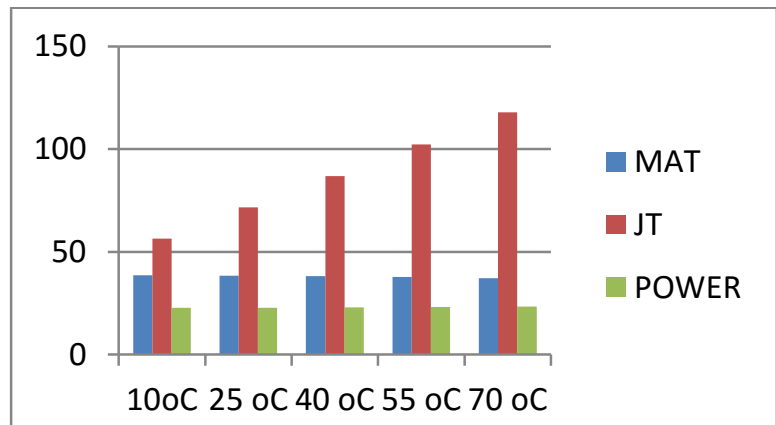

Figure 3: Graphical representation of MAT, JT, and LP for LVCMOS_33

Table 4: Analysis of MAT, JT, and LP for LVCMOS_15 IO standard

\begin{tabular}{|l|l|l|l|}
\hline & MAT & JT & POWER \\
\hline $10^{\circ} \mathrm{C}$ & 73.5 & 21.5 & 5.598 \\
\hline $25^{\circ} \mathrm{C}$ & 73.5 & 36.5 & 5.616 \\
\hline $40^{\circ} \mathrm{C}$ & 73.4 & 51.6 & 5.649 \\
\hline $55^{\circ} \mathrm{C}$ & 73.3 & 66.7 & 5.710 \\
\hline
\end{tabular}




\begin{tabular}{|l|l|l|l|}
\hline $70{ }^{\circ} \mathrm{C}$ & 73.1 & 81.9 & 5.815 \\
\hline
\end{tabular}

There is $0.544 \%, 73.74 \%, 3.73 \%$ reduction in MAT, JT, and POWER respectively when we range down ambient temperature from $70{ }^{\circ} \mathrm{C}$ to $10^{\circ} \mathrm{C}$

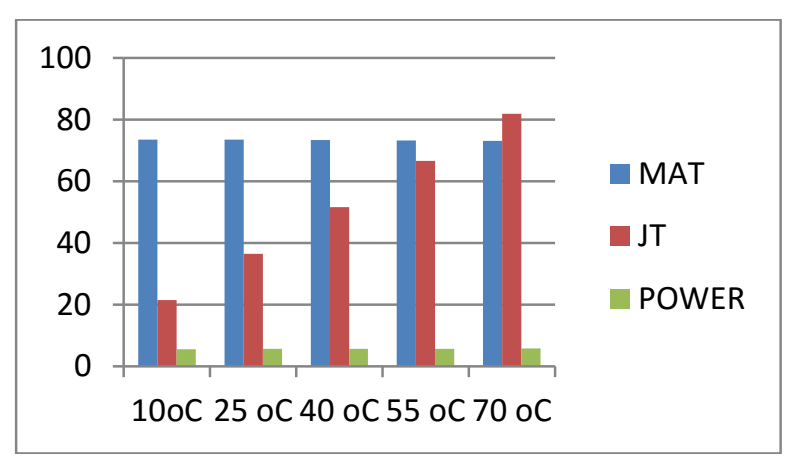

Figure 4: Graphical representation of MAT, JT, LP for LVCMOS_15

\section{RESULTS}

\section{A. POWER ANALYSIS}

Table 5: Leakage Power analysis for various IO standards

\begin{tabular}{|l|l|l|l|l|}
\hline & Lvcmos 15 & Lvcmos 18 & Lvcmos33 & Lvcmos25 \\
\hline $10^{\circ} \mathrm{C}$ & 5.598 & 7.517 & 22.658 & 13.288 \\
\hline $25^{\circ} \mathrm{C}$ & 5.616 & 7.537 & 22.731 & 13.322 \\
\hline $40^{\circ} \mathrm{C}$ & 5.649 & 7.576 & 22.855 & 13.385 \\
\hline $55^{\circ} \mathrm{C}$ & 5.710 & 7.647 & 23.055 & 13.493 \\
\hline $70^{\circ} \mathrm{C}$ & 5.815 & 7.767 & 23.360 & 13.699 \\
\hline
\end{tabular}

There is $3.73 \%, 3.21 \%, 3.005 \%, 3.002 \%$ reduction in leakage power for LVCMOS_15, LVCMOS_18,LVCMOS_33, LVCMOS_25 respectively when we scale down ambient temperature from $70^{\circ} \mathrm{C}$ to $10^{\circ} \mathrm{C}$

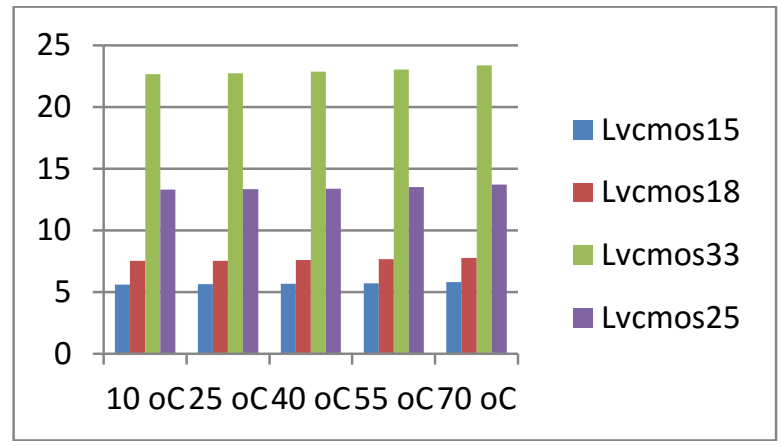

Figure 5: Graphical Power analysis for various IO standards

\section{B. THERMAL ANALYSIS}

Table 6: Thermal Analysis in terms of MAT for various IO standards

\begin{tabular}{|l|l|l|l|l|}
\hline & Lvcmos15 & Lvcmos18 & Lvcmos33 & Lvcmos25 \\
\hline $10^{\circ} \mathrm{C}$ & 73.5 & 69.6 & 38.5 & 57.7 \\
\hline $25^{\circ} \mathrm{C}$ & 73.5 & 69.5 & 38.4 & 57.7 \\
\hline $40^{\circ} \mathrm{C}$ & 73.4 & 69.5 & 38.1 & 57.5 \\
\hline $55^{\circ} \mathrm{C}$ & 73.3 & 69.3 & 37.7 & 57.3 \\
\hline $70^{\circ} \mathrm{C}$ & 73.1 & 69.1 & 37.1 & 57.0 \\
\hline
\end{tabular}


There is $0.544 \%, 0.71 \%, 3.63 \%, 1.21 \%$ reduction in MAT for LVCMOS_15, LVCMOS_18, LVCMOS_33, LVCMOS_25 respectively when we range down ambient temperature from $70^{\circ} \mathrm{C}$ to $10^{\circ} \mathrm{C}$.

Table 7: Thermal Analysis in terms of JT for various IO standards

\begin{tabular}{|l|l|l|l|l|}
\hline & Lvcmos 15 & Lvcmos18 & Lvcmos33 & Lvcmos25 \\
\hline $10^{\circ} \mathrm{C}$ & 21.5 & 25.4 & 56.5 & 37.3 \\
\hline $25^{\circ} \mathrm{C}$ & 36.5 & 40.5 & 71.6 & 52.3 \\
\hline $40^{\circ} \mathrm{C}$ & 51.6 & 55.5 & 86.9 & 67.5 \\
\hline $55^{\circ} \mathrm{C}$ & 66.7 & 70.7 & 102.3 & 82.7 \\
\hline $70^{\circ} \mathrm{C}$ & 81.9 & 85.9 & 117.9 & 98.0 \\
\hline
\end{tabular}

There is $73.74 \%, 70.43 \%, 52.00 \%, 61.93 \%$ reduction in JT for LVCMOS_15, LVCMOS_18, LVCMOS_33, LVCMOS_25 respectively when we range down ambient temperature from $70^{\circ} \mathrm{C}$ to $10^{\circ} \mathrm{C}$.

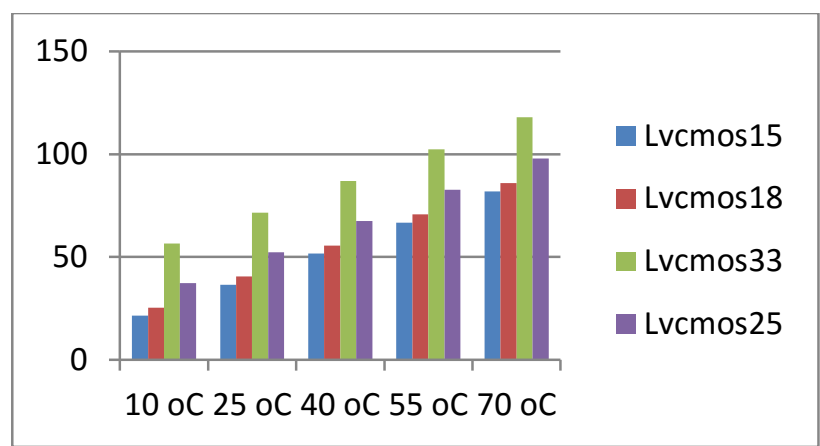

Figure 6: Graphical Thermal analysis for various IO standards

\section{III.CONCLUSION}

Low Power Energy efficient Vedic multiplier design is possible with LVCMOS I/O standard. Variation in ambient temperature will create a significant variation in Junction temperature. But, there only a gradual change in MAT and LP with change in temperature for uniform IO standard. There is $3.73 \%, 3.21 \%, 3.005 \%, 3.002 \%$ reduction in leakage power, there is $0.544 \%, 0.71 \%, 3.63 \%, 1.21 \%$ reduction in MAT and there is $73.74 \%, 70.43 \%, 52.00 \%, 61.93 \%$ reduction in JT for LVCMOS_15, LVCMOS_18, LVCMOS_33, LVCMOS_25 respectively when we range down ambient temperature from $70^{\circ} \mathrm{C}$ to $10^{\circ} \mathrm{C}$.

\section{IV.FUTURE SCOPE}

By moving from one IO standard LVCMOS to others such as HSTL or HSTL_DCI or SSTL or LVDCI or HSLVDCI, we can discover new alternative to decrease power debauchery. Power debauchery is certain to diverge with various IO standards and the reason after that. This is Kintex-7 based on $28 \mathrm{~nm}$ FPGA. There is a wide area to explore this design in latest FPGA's such as Virtex-7, it is based on 28- nm FPGA which makes us proficient to obtain the advantage of deeper sub-micron circuit.

\section{REFERENCES}

1) R. Sridevi, Anirudh Palakurthi, Akhila Sadhula, Hafsa Mahreen" Design of a High Speed Multiplier (Ancient Vedic Mathematics Approach)",2004.

2) C.Roth Jr. "Digital Systems Design using VHDL,"Thomson Brooks/Cole, 7th reprint, 2005.

3) J.Swami Sri Bharati Krisna Tirthaji Maharaja,Vedic Mathematics: Sixteen Simple Mathematical Formulae from the Veda, Delhi (1965). 
4) H. Thapliyal and M. B. Shrinivas and H. Arbania, "Design and Analysis of a VLSI Based High Performance Low Power Parallel Square Architecture", Int. Conf. Algo. Math.Comp. Sc., LasVegas, June 2005, pp. 72-76.

5) B. Pandey, T. Kumar, T. Das and J. Kumar " Thermal Mechanics Based Energy Efficient FIR Filter for Digital Signal Processing", Applied Mechanics and Materials (AMM) Journal, ISSN:16627482(online version), 2014.

6) W. et.al ,Huang. "Compact thermal modeling for temperature-aware design”, In Proceedings of the 41st annual Design Automation Conference, pp. 878-883, 2004.

7) B S Chowdhary et.al. "Thermal Aware Energy Efficient ALU Design on Ultra Scale FPGA", 1st International Conference on Modern Communication \& Computing Technologies - (MCCT'14)QUEST Pakistan, 26th - 28th February, 2014.

8) UY Ogras, J. Hu, R. Marculescu, "Key research problems in NoC design: a holistic perspective". In Proceedings of the 3rd IEEE/ACM/IFIP international conference on Hardware/software codesign and system synthesis, pp. 69-74, 2005. 